\title{
Reflexões feministas sobre escuta e democracia: experiências das mulheres na construção de paz na Colômbia
}

\section{Feminist reflections on listening and democracy: women's experiences in peace building in Colombia}

\section{Reflexiones feministas sobre la escucha y la democracia: experiencias de las mujeres en la construcción de la paz en Colombia}

\author{
Pedro Barbabela ${ }^{a}$ (1) e Yulieth Martínez Villalba ${ }^{b}$ \\ a Mestrando em Ciência Política pela Universidade Federal de Minas Gerais (PPGCP/UFMG). Pesquisador do Núcleo de Estudos e \\ Pesquisa sobre a Mulher (NEPEM/UFMG) e do Centro do Interesse Feminista e de Gênero (CIFG/UFMG). Analista de Pesquisa na \\ TODXS Núcleo (http://nucleo.todxs.org). Bacharel em Relações Internacionais pela Pontifícia Universidade Católica de Minas Ge- \\ rais (PUC Minas), com período sanduíche na Universidade do Porto, em Portugal, onde estudou Línguas e Relações Internacionais. \\ E-mail: pedro.barbabela@gmail.com. Universidade Federal de Minas Gerais (UFMG) \\ ${ }^{\text {b }}$ Mestranda em Ciência Política pela Universidade Federal de Minas Gerais (PPGCP/UFMG), Especialista em Epistemologias do \\ Sul pelo Conselho Latino-Americano de Ciências Sociais (CLACSO) e o Centro de Estudos Sociais da Universidade de Coimbra, \\ Profissional de Negócios Internacionais pela Universidad del Magdalena da Colômbia (Unimag), com período sanduíche na Univer- \\ sidade Estatal Paulista "Júlio de Mesquita Filho" no Brasil. Pesquisadora da Rede Interinstitucional de Política Externa e Regime \\ Político (RIPPERP) e do Grupo de Pesquisa em Conflicto y Relaciones Intemacionales (Unimag). E-mail: yulieth.martinez08@, \\ gmail.com. Universidade Federal de Minas Gerais (UFMG)
}

Resumo: A assinatura do termo de compromisso para o término do conflito armado na Colômbia no ano de 2012, significou um importante avanço na tentativa de criar uma paz mais inclusiva e duradoura que reconhecesse o lugar das experiências individuais no processo de paz no país. O presente artigo busca compreender a participação dos movimentos de mulheres e feministas ao longo do processo de paz na Colômbia (2012-2016), a partir de discussões presentes na teoria democrática contemporânea. Por meio de uma abordagem feminista, realizamos uma etnografia de documentos produzidos sobre as conferências e fónuns de vítimas, que contaram com uma intensa participação de mulheres, tentando compreender as contribuições dos movimentos para a construção democrática na Colômbia. Como resultado, percebemos que a participação das mulheres em espaços de deliberação, contribuiu para a ampliação da compreensão do conflito e possibilitou a incorporação de demandas diferenciadas no documento final.

Palavras-chave: Teoria democrática; Movimentos de mulheres e feministas; Acordo de La Habana; Processo de Paz; Colômbia.

Como citar o artigo: BARBABELA, P.; VILLALBA, Y. M. Reflexões feministas sobre escuta e democracia: experiências das mulheres na construção de paz na Colômbia. Revista de Ciências Humanas, Florianópolis, v. 53, 2019 DOI: $10.5007 / 2178-4582.2019 . e 67215$ você pode compartilhar, adaptar, para qualquer fim, desde que atribua a autoria da obra, forneça um link para a licença, e indicar se foram feitas alterações. 


\begin{abstract}
The signing of the commitment term for the end of the armed conflict in Colombia in 2012 was a major step forward in the attempt to create a more inclusive and lasting peace that acknowledge the place of individual experiences in the country's peace process. This paper seeks to understand the participation of women's and feminist movements throughout the peace process in Colombia (2012-2016), based on discussions in contemporary democratic theory. Through a feminist approach, we have produced an ethnography of documents produced on victims' conferences and forums, which were heavily attended by women, trying to understand the contributions of the movements to the democratic construction in Colombia. As a result, we realized that the participation of women in deliberation spaces contributed to broadening the understanding of the conflict and allowed the incorporation of differentiated demands in the final document.
\end{abstract}

Keywords: Democratic theory; Women's and feminist movements; La Habana Agreement; Peace Process, Colombia.

Resumen: La firma del plazo de compromiso para el fin del conflicto armado en Colombia en 2012 fue un gran paso adelante en el intento de crear una paz más inclusiva y duradera que reconociera el lugar de las experiencias individuales en el proceso de paz del país. Este artículo busca comprender la participación de los movimientos feministas y de mujeres en todo el proceso de paz en Colombia (2012-2016), a partir de las discusiones en la teoría democrática contemporánea. A través de un enfoque feminista, hemos producido una etnografía de documentos producidos en conferencias y foros de víctimas, a los que asistieron muchas mujeres, tratando de comprender las contribuciones de los movimientos a la construcción democrática en Colombia. Como resultado, nos dimos cuenta de que la participación de las mujeres en los espacios de deliberación contribuyó a ampliar la comprensión del conflicto y permitió la incorporación de demandas diferenciadas en el documento final.

Palabras clave: Teoría democrática; Movimientos de mujeres y feministas; Acuerdo de La Habana; Proceso de paz; Colombia

\title{
1 INTRODUÇÃO
}

Por muito tempo a sociedade colombiana se organizou em torno do conflito armado. A forma pela qual são formuladas as políticas públicas, os planos de desenvolvimento econômico, as estratégias de internacionalização (ou regionalização) do país e até a própria construção identitária da sua população, foram atravessados pelo contexto de disputas armadas. O conflito, embora generalizado e presente no imaginário da sociedade colombiana, não afeta a todos os indivíduos por igual. A multiplicidade de agentes envolvidos, atuando em regiões especificas, sob condições diversas, fez com que certos indivíduos ou grupos estivessem mais vulneráveis às ações advindas do conflito, a esses indivíduos se lhes conhece com o nome de vitimas do conflito armado.

Resolver o problema do conflito na Colômbia, passa por reconhecer às vítimas, garantindo seu direito à verdade, justiça, reparação integral e sobretudo dando garantias de não repetição. Portanto, integrá-las ao processo de paz, converteu-se em uma condição indispensável para que o "processo acabasse gozando de legitimidade, representando diretamente os grupos mais vulneráveis e tendo potencial para ser sustentável" (BRETT, 2017, p 10). Desta maneira, foram estabelecidos distintos mecanismos de participação para inclusão da sociedade civil e principalmente das vítimas no processo de paz, podendo destacar os seguintes: o envio de propostas à mesa de diálogo através de prefeitos e governadores das distintas regiões do país; a realização de Fóruns territoriais e nacionais com/sobre as vítimas e a conformação de delegações de vítimas que viajaram à La Habana para conversar com as partes envolvidas.

Um dos mecanismos mais importante foi os Fóruns de vítimas, sobre o qual se centra a análise do presente artigo. É importante ressaltar que, esses fóruns possibilitaram um encontro sem precedentes das vítimas do conflito, pois através desses espaços foi possível desenvolver uma série de ações que amplificassem suas vozes e melhorassem os canais para serem ouvidas/os. Para tanto, realizamos uma etnografia de documentos (VIANNA, 2014) a partir de fontes oficiais, relatórios gerais de distintas instituições envolvidas no processo de paz e artigos científicos; com a finalidade de compreender a forma como se deu a participação das mulheres nessas instâncias deliberativas e como as demandas e experiências dessas agentes foram incluídas nos documentos resultantes dos encontros. 
O artigo é atravessado por discussões da teoria democrática deliberativa e de novas abordagens da democracia, como a democracia sensorial, que forneceram as bases teóricas para decifrar as contribuições dadas pelos fóruns de vítimas ao processo de paz, sobretudo, à reconstrução dos laços sociais da Colômbia. Nesse sentido, o artigo foi construído a partir de dois elementos principais: (i) a participação das vítimas em geral nos fóruns e, (ii) a participação das mulheres como vítimas específicas do conflito.

$O$ enfoque dado às mulheres neste artigo se justifica a partir do entendimento de que elas têm sido expostas a diferentes formas de violência de maneira desproporcional durante as cinco décadas do conflito colombiano (BRETT, 2017). Sendo assim, mostra-se relevante entender a forma como essas agentes foram/são capazes de enfrentar e resistir a exposição de distintos níveis de violências, conseguindo fazer com que suas vozes sejam ouvidas e que suas demandas, transmitidas a partir de narrativas de suas experiências no conflito, passassem a ser inseridas no processo de construção de paz.

O artigo está dividido em três seções. A primeira, traz reflexões sobre os mecanismos deliberativos, especificamente sobre a importância da estratégia das narrativas (storytelling) e sua utilização durante o processo de construção de paz na Colômbia. Posteriormente, abordaremos os fóruns de vítimas como espaços de escuta e valorização das vozes destas/destes agentes, ressaltando a importância da escuta para o fortalecimento democrático. Tais fóruns, permitiram a formulação de propostas que visavam o fortalecimento da democracia no país. Na seção seguinte, abordaremos o papel dos movimentos de mulheres e feministas ${ }^{1}$ nas Conferências e ao longo do processo de paz, destacando algumas das principais contribuições e ações empreendidas por essas agentes durante o período. Nessa seção, buscaremos conjugar as ações com as formulações de autoras feministas sobre o tópico feminismo e democracia. Por fim, concluímos nosso artigo apresentando as principais ganhos no que tange as possibilidades de análise ao conjugar diferentes enquadramentos de teorias democráticas ao caso colombiano.

\section{2 “CONTO, LOGO EXISTO”: DELIBERANDO EM MEIO AO CONFLITO}

As abordagens da teoria deliberativa trouxeram valiosos aportes para o entendimento dos processos sociais. A forma como nos relacionamos, participamos e (des)construímos o mundo que nos rodeia por meio da linguagem possibilitou a reapropriação de fenômenos políticos, assim como também influenciou a criação de mecanismos deliberativos concretos, que são usados de distintas maneiras nas sociedades atuais.

As conferências, fóruns e assembleias, assim como outras formas menos formalizadas onde são empregadas técnicas deliberativas, têm se estendido por vários países como mecanismos de participação política. Tais mecanismos possibilitam o encontro e discussão entre distintas visões de mundo, com o objetivo de gerar ações efetivas, como é o caso das políticas públicas. No entanto, as formas como são aplicados tais procedimentos e a maneira como se realizam "as trocas argumentativas" de razões (MENDONÇA, 2016), dependem das condições especificas nas quais se assenta cada sociedade. Assim, em sociedades com fragmentações profundas ${ }^{2}$, as quais geram situações de violência, os processos deliberativos operam em meio a um ambiente de instabilidade e inquietação; enquanto, em sociedades com condições "pacíficas" os mesmos processos apresentam dinâmicas de maior estabilidade, que se traduzem em processos de construção social mais constantes e contínuos. Nesse

1 Utilizamos o termo movimentos/organizações de mulheres e feministas para reconhecer as diferentes associações e pertencimentos das mulheres a determinados grupos sociais. Na Colômbia, por exemplo, durante o processo de construção de paz, diversas mulheres, feministas ou não, participaram de negociações marcadas por conflito e convergências em relação a questões em disputa.

2 Termo utilizado na obra de Steiner et al. (2017) para descrever países que passam por situação de quebra de vínculos sociais devido a conflitos internos, guerras, etc.

3 Reconhecendo que não existem sociedades sem conflitos, usamos o termo "condições pacíficas", para nos referirmos a aquelas sociedades com ausência de conflitos profundos entre segmentos sociais ou mesmo guerras. 
sentido, e de acordo com Steiner et al (2017), ao mesmo tempo que a deliberação é particularmente importante e necessária para países com divisões societais profundas, é precisamente nesses países onde a deliberação é mais difícil de estabelecer.

Admite-se que não existem sociedades que se desenvolvam na ausência dos conflitos. De acordo com Galtung (1996), tais dinâmicas são inerentes a todos os sistemas vivos enquanto portadores de objetivos. Assim, o conflito é algo comum a todas as sociedades humanas, porém não todos se expressam de forma violenta. É por isso que, a maioria de abordagens contemporâneas de conflitologia (VINYAMATA, 2014), problematizam o conflito social, não mais como uma distorção das relações humanas e sim como parte fundamental delas. Assim, os conflitos apresentariam variações de dinâmicas sociais que seriam alteradas de maneiras e intensidades diferentes ao longo de um período histórico, as guerras seriam uma de suas manifestações mais intensas.

Mensurar a intensidade dos conflitos não é tarefa fácil, assim como também não faz parte do objetivo do presente artigo. Não obstante, utilizamos o estudo realizado pelo Heidelberg Institute for International Conflict Research (HIIK, por seu nome em alemão), denominado como "Conflito Barômetro", para situar o conflito colombiano dentro das discussões sobre intensidades dos conflitos. O objetivo deste estudo é apresentar um panorama dos conflitos a nível mundial a partir de seu indicador de intensidade. Deste modo, a metodologia do estudo define a intensidade dos conflitos como "um atributo da soma das medidas de conflito em um determinado conflito político, dada uma área geográfica especifica e um determinado espaço de tempo" (HIIK, 2018, p. 7). A partir daí, o estudo classifica os conflitos com base nos níveis de violência, criando cinco graus de intensidade com suas respectivas terminologias e classificando-os segundo três classes.

Figura 1- Indicadores operacionais do conceito de "intensidade de conflito" de acordo com o HIIK.

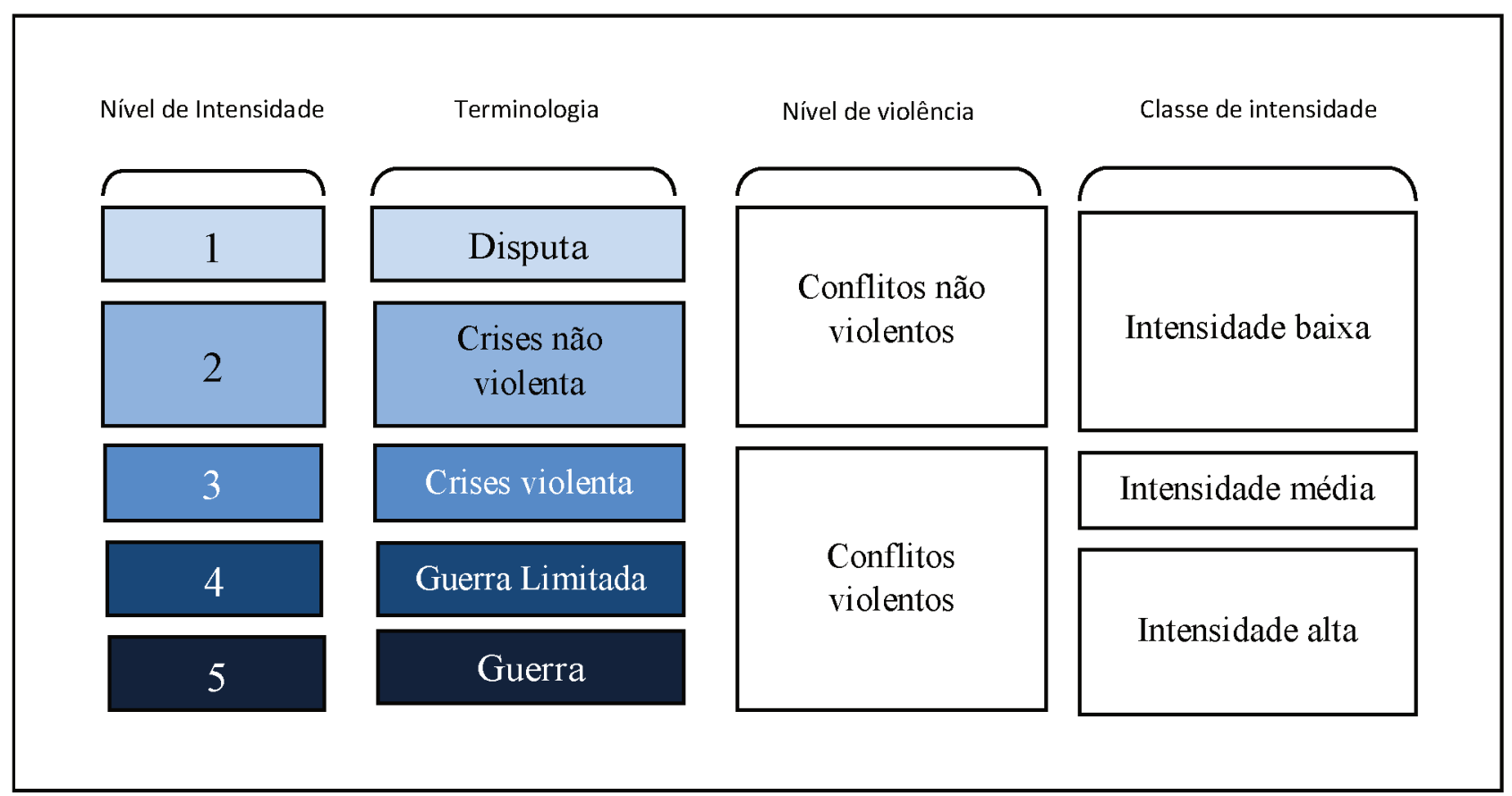

Fonte: HIIK (2018)

Desde que começou o estudo em 1992, a Colômbia foi colocada como um dos principais focos de conflito na América (HIIK, 1992). Desde então o conflito colombiano foi classificado nos níveis mais altos dessa escala, sendo catalogado como "guerra" num primeiro momento e em 2004 passa a ser 
denominado como uma "crise severa"4. Atualmente, o conflito na Colômbia encontra-se classificado no nível 4 denominado "guerra limitada" (HIIK, 2018). Assim, não é estranho que o país conte com indicadores profundos de desigualdade (WORLD INEQUALITY DATABASE, 2018), que permanecem como a causa e o efeito de um conflito interno armado de mais de 50 anos.

O conflito foi se convertendo em um elemento definidor da realidade social do país, sendo reflexo das divisões estruturais da sociedade colombiana, que se radicalizaram mediante o surgimento de grupos específicos de resistência e contra resistência. A luta armada parece ter virado um atributo dessa sociedade, e estar no meio do conflito passou a ser um elemento identitário que atravessa a todas/ os as/os colombianas/os, de inúmeras e variadas formas, mas a todos sem exceção. Desta maneira, a resolução do conflito, é tudo, menos uma tarefa fácil.

A decisão política de colocar fim ao conflito armado na Colômbia por meio do diálogo no ano de 2012, dividiu novamente as opiniões de uma sociedade historicamente fragmentada, onde uma das principais causas da violência tem sido a intolerância (URIBE CELIS, 2011). No entanto, a tentativa de reunir posições adversas, opiniões contrárias sobre a interpretação do conflito, seus agentes, suas consequências e, sobretudo, suas soluções têm sido colocadas a prova várias vezes ao longo de pelo menos quatro processos de paz $^{5}$ com grupos guerrilheiros na história recente do país. Tais situações, podem nos dar indícios para pensar que a deliberação é perfeitamente possível em uma sociedade altamente segmentada ao ser uma "prática que ocorre também em meio a disputas de poder e interesses" (MENDONÇA, 2009, p. 508) e que, contrariamente ao que críticos da teoria deliberativa tem sinalizado, "os ideias habermasianos que estão na base da perspectiva deliberacionista (...) evidenciam a possibilidade e a necessidade de diálogo entre diferentes posições, acabando por promovê-las" (MENDONÇA, 2009, p. 509).

As apostas sociais em torno do diálogo como ferramenta de resolução de conflitos que colocam o "raciocínio público como centro da justificação política" (COHEN, 1997, p. 413), se converteram em opções reais, capazes de serem colocadas em prática em diversas sociedades democráticas. É preciso notar que, tais procedimentos deliberativos não propõem o estabelecimento de um consenso, nem a alteração das preferências dos cidadãos (COHEN, 1997); pelo contrário: baseiam-se em um processo dialógico que coloca ênfase na troca respeitosa de argumentos, entendendo que tais argumentos são plurais e muitas vezes até antagônicos.

Esse cenário de "pluralismo razoável" ao qual se refere Cohen (1997) nos ajuda a entender "que de fato existem compreensões de valor distintas e incompatíveis, cada uma razoáveis, para o qual as pessoas são atraídas sob condições favoráveis para o exercício de sua razão prática" (COHEN, 1997, p. 408). Essas compreensões de valor nem sempre são expressas por meio de argumentos de base racional, longe disso, a possibilidade de uma razoabilidade em vez de uma racionalidade, contribui para entender a multiplicidade de manifestações comunicativas dentro de um processo deliberativo, as quais não demandam a ausência de expressão emocional (YOUNG, 1996). Assim, para Dryzek (2009), a deliberação pode estar aberta a uma variedade de formas de comunicação como a retórica, os testemunhos, storytelling (contação de histórias) e o humor; já que a comunicação política do mundo real geralmente mistura diferentes formas e mesmo aquelas que não envolvem argumentos expressados dialogicamente, podem ser efetivas em induzir reflexão. Nessa mesma direção, Krause (2008, p.

4 Deve se esclarecer que, nos primeiros anos o estudo só objetivava classificar os conflitos com base em dois níveis: "crise severa" e a "guerra", respetivamente. Com o passo do tempo a mensuração e a escala foram ficando mais complexas, até chegar no estado que se encontra atualmente.

5 A Colômbia tem passado pelo menos por 4 processos de paz com grupos guerrilheiros ao longo da sua história recente e várias aproximações que não se concretizaram em processos de paz. Os processo de paz aos quais nos referimos são os seguintes: Processo de Paz de La Uribe-Meta (1982-1986), Processo de paz com o Coordenador de Guerrilha Simón Bolívar (CGSB) em Caracas e Tlaxcala (abril-junho de 1992), Processo de negociação entre as FARC-EP e a administração de Andrés Pastrana em San Vicente del Caguán (Caquetá, 1998-2002), Processo de negociação entre as FARC-EP e a administração de Juan Manuel Santos em La Habana (2012-2016) (PÉREZ, 2018). 
118) acrescenta que "a expressão do sentimento pode contribuir de maneira valiosa para a deliberação pública, mesmo quando não assume uma forma explícita de argumentação".

O último processo de paz na Colômbia, se iniciou formalmente no dia 4 de setembro de 2012. AMesa de Negociação foi composta por delegados de duas das partes armadas do conflito: o Estado Colombiano, representado nesse momento pelo governo de Juan Manuel Santos e as Forças Armadas Revolucionárias da Colômbia - Exército do Povo (FARC-EP). Por meio do "Acuerdo General para la Terminación del Conflicto y la Construcción de una Paz Estable y Duradera" assinado entre as partes em 26 de agosto de 2012, foi proposto uma série de mecanismos de participação para incluir a sociedade civil, de forma direta e indireta, para que pudesse contribuir à solução do conflito. Os mecanismos mais importantes nesse sentido são: a conformação de delegações, a realização de fóruns nacionais/territoriais e o envio de propostas sobre os pontos da agenda canalizados pelos prefeitos dos distintos municípios da Colômbia.

Em meio do conflito, sentimentos e emoções são mais que uma forma de expressão, são uma forma de resistência e de luta. É por isso que formas e propostas deliberativas no centro do conflito não poderão nunca fugir do seu encontro marcado com as emoções e as afetividades das mulheres e homens que passaram por tais experiências. No entanto, são precisamente essas expressões as que contribuem para enriquecer os cidadãos e, ao mesmo tempo, melhoram a deliberação pública (KRAUSE, 2008). Para além de falar sobre as experiências das vítimas, é necessário ter em mente que esses espaços de deliberação devem ser abertos para um processo de escuta, onde os agentes estejam dispostos a compreender a realidade e a partir disso propor mudanças no plano político.

A existência de uma diversidade de espaços deliberativos, institucionalizados ou não, tornou-se marca do processo de construção da paz na Colômbia. Para além dos fóruns de vítimas, diversos conselhos ocorreram no país organizados por diversos movimentos sociais que utilizavam esses espaços para influenciar a construção da opinião pública sobre o acordo. Nesses ambientes, diferentes técnicas comunicativas, como as narrativas e o storytelling, foram usadas para afirmar e localizar o papel da experiência individual na resolução do conflito armado.

Para Boswell (2012), a existência dessa série de espaços deliberativos conectados entre si pode ser analisada a partir da virada sistêmica, na qual há a noção de que deliberação ocorre em uma diversidade de esferas diferenciadas e interconectadas. Essa situação possibilita a emergência de diferentes dispositivos comunicativos cruciais, pelo qual os indivíduos se expressam sobre questões complexas e contestadas. Essas novas formas de ações comunicativas explicitam as potencialidades da teoria deliberativa, ao informar a existência e importância de uma série de dispositivos que não se baseiam, necessariamente, na troca de razões, mas que reconheçam as subjetividades dos indivíduos.

Autores como Young (1990, 1996), Ryfe (2006), Black (2008), Fisher (2009), Dryzek (2010), Boswell (2012) e outros, contribuíram para o entendimento de pluralismo discursivo dentro da teoria deliberativa, através do estabelecimento de pontes compreensivas entre a deliberação e as emoções, as narrativas, a retórica, o testemunho, a contação de história e outros mecanismos comunicativos. Para fins do presente estudo, focalizaremos nos trabalhos de Laura Black e David Ryfe que possuem trabalhos convergentes e complementares sobre o uso da contação de histórias (storytelling) como um dispositivo facilitador dentro da teoria deliberativa.

Segundo Laura Black (2008), o estudo das histórias proporciona uma abordagem centrada no discurso capaz de esclarecer as interações mantendo seu potencial dialógico, além de facilitar aos ouvintes a compreensão de opiniões e perspectivas do narrador. Assim, contar histórias fornece aos membros do grupo uma oportunidade de abertura de diálogo e relação entre o "eu" e o "outro". A autora argumenta que as histórias têm um grande potencial de influenciar positivamente o processo deliberativo através da coesão de grupos que passam a identificar identidades coletivas e opiniões/valores em comum com outros membros de seu grupo (BLACK, 2008). É através da contação de histórias, que esses agentes se reconhecem e se percebem como parte viva e importante de uma tentativa de reconstrução, que os atravessa e os coloca como parte fundamental, permitindo-lhes recuperar sua identidade. 
Na mesma linha de Black (2008), David Ryfe (2006) busca entender o papel da contação de história para a formação das identidades. Para o autor, os indivíduos contam histórias para estabelecer uma identidade comum sobre uma determinada questão. Além disso, as histórias seriam responsáveis por estabelecer relações baseadas na civilidade e na amizade entre os indivíduos (RYFE, 2006).

No caso da construção de paz na Colômbia, o storytelling é um mecanismo central para a compreensão da participação das mulheres, nos fóruns de vítimas que ocorreram no país. Assim, por exemplo, diversas organizações de mulheres criaram campanhas de conscientização como forma de influenciar a opinião pública sobre a violência desproporcional que as mulheres vivenciaram durante o conflito e a necessidade do acordo englobar o ponto de vista dessas vítimas.

De forma conjunta, diversas organizações como a Corporación Sisma Mujer, a Corporación Humanas, Red Nacional de Mujeres e o movimento No es hora de callar lançaram uma série de vídeos para uma campanha, que recebeu o nome de "Cinco Claves para erradicación de la violencia sexual" (HUMANAS COLOMBIA, 2016; HUMANAS COLOMBIA, CORPORACIÓN SISMA MUJER, RED NACIONAL DE MUJERES, 2016). A iniciativa buscou articular os discursos e as vivências de diversas mulheres que estiveram envolvidas no conflito, fossem elas ativistas dos direitos das mulheres ou então mulheres vítimas de violência, para conscientizar o público em geral.

Por trás da campanha, esse agrupamento de organizações buscou, também, pressionar as partes negociadoras do acordo para que reconhecessem que o emprego da violência sexual foi utilizado como instrumento para alcançar objetivos políticos. Ademais, a afirmação por parte das autoridades públicas em relação ao emprego dessa prática faria com que o sistema de justiça reconhecesse o caráter público desse tipo de violência, visto que sempre fora considerado algo privado (HUMANAS COLOMBIA, CORPORACIÓN SISMA MUJER, RED NACIONAL DE MUJERES, 2016). O emprego de narrativas, contação de história e testemunhos influenciaram fortemente a mobilização da sociedade colombiana e de algumas autoridades que se comprometeram na defesa dos direitos das mulheres

A estratégia de publicização das histórias das vítimas de violência sexual e das falas de ativistas de direitos das mulheres, torna perceptível como esse meio foi utilizado para afetar a formação da opinião pública e para moldar, consequentemente, o "pacote" de políticas presente no acordo de paz. Assim, no caso colombiano, torna-se claro como essas diferentes formas de comunicação foram, e ainda são, de grande importância na dinâmica política, principalmente nas dinâmicas de interação entre os movimentos de mulheres e feministas e o Estado na Colômbia.

\section{FÓRUNS DE VÍTIMAS NA COLÔMBIA: ESPAÇOS DE ESCUTA E CONSTRUÇ̃̃o DEMOCRÁTICA}

No que tange os mecanismos de participação dispostos para vincular a sociedade civil ao processo de paz, o envio de propostas foi o primeiro a ser estabelecido entre os 2012 e 2014. Neste, foram recebidas e encaminhadas à Mesa de Negociação aproximadamente 9306 propostas (BRETT, 2017, p. 12). Paralelamente, começaram a ser organizados os fóruns nacionais e regionais, sobre quatro dos seis pontos da agenda de negociação: Reforma Rural Integral, Participação Política, Solução do Problema das Drogas Ilícitas e as Vítimas do Conflito6; os quais estiveram a cargo da Unidade para o Desenvolvimento das Nações Unidas em parceria com a Universidad Nacional de Colômbia. Tais fóruns foram organizados conforme iam sendo solicitados pelos delegados das FARC-EP e o Governo da Colômbia, mediante comunicados conjuntos de caráter público, onde davam as diretrizes sobre o que consideravam pontos principais de discussão nesses espaços, além de estabelecer as regiões onde esses fóruns deveriam ser realizados.

6 A agenda de negociação do Processo de Paz girou em torno de 6 pontos importantes, sendo eles: Reforma Rural Integral, Participação Política, Cesse de Hostilidades Bilaterais e Definitivas / Reincorporação das FARC-EP à Vida Civil, Solução do Problema das Drogas Ilícitas, as Vítimas do Conflito e Mecanismos de Implementação e Verificação. 
O direcionamento que seria dado à pauta de vítimas durante a negociação, foi definido pelo Comunicado Conjunto (No. 37) de 7 de junho de 2014, intitulado: "Declaración de principios para la Discusión del punto 5 de la Agenda: Víctimas". Nele, não só se dispuseram os 10 princípios gerais ${ }^{7}$ para abordar a discussão sobre as vítimas do conflito durante a negociação, como também se solicitou à Organização das Nações Unidas na Colômbia e ao "Centro de Pensamiento y Seguimiento al Diálogo de Paz" da Universidad Nacional que organizasse três fóruns regionais (Villavicencio, Barrancabermeja e Barranquilla) e um fórum nacional (Cali). O Objetivo desses fóruns era criar um espaço institucional que possibilitasse a participação das vítimas no processo e contribuísse com propostas concretas sobre os 10 pontos estabelecidos, que viessem a ser pensadas e formuladas a partir das experiências das vítimas.

Ainda mais importante, pela primeira vez em um processo de paz na Colômbia, as partes propuseram a inclusão formal das vítimas na Mesa de Negociação, por meio da formação de cinco delegações, cada uma com 12 delegadas/os, que viajariam até Havana para se reunir com as comissões das FARC-EP e do Governo. Finalmente, mas não menos importante, esse mesmo documento também estabeleceu a criação de uma subcomissão de gênero, a qual seria constituída por integrantes de ambas delegações, para revisar e garantir que os acordos alcançados possuíssem um enfoque diferencial e transversal de gênero.

Com relação à composição das delegações de vítimas que viajariam a Havana, as partes estabeleceram que deveriam ser compostas "de maneira a assegurar a representação plural e equilibrada das diferentes vítimas, bem como os diferentes fatos vitimadores, sem pretender que uma delegação possa representar os milhões de vítimas que o conflito armado nos deixou" (COMUNICADO CONJUNTO NO. 37, 2014, p. 3). Nesse sentido, o modelo colombiano de incorporação da participação direta das vítimas do conflito armado na mesa de negociação representa uma experiência inovadora no cenário de construção da paz em nível global, na medida em que fornece às vítimas a capacidade de se constituírem como agentes políticos capazes de apresentar suas demandas de reconhecimento para a estrutura de paz e justiça transicional (BRETT, 2017, p. 18).

Os fóruns, por outro lado, representaram uma primeira experiência através da qual as vítimas do conflito puderam participar coletiva e publicamente, tendo como objetivo principal "receber e sistematizar as propostas das vítimas e da cidadania com relação ao ponto 5 (Vítimas), para posteriormente serem enviadas por meio dos países participantes da Mesa de Negociação" (BRETT, 2017, p. 24). Desta maneira, as instituições organizadoras dos fóruns se esforçaram para reconhecer as experiências das vítimas, facilitando suas vozes, nas palavras de Jenny Pearce (2012), por meio de procedimentos deliberativos que permitissem e/ou motivassem dispositivos comunicativos informais, simbólicos e vivenciais, com a finalidade de garantir sua participação. Nesse sentido, a ideia era empoderar as vítimas, através da possibilidade de serem ouvidas, assim como relata o padre Francisco La Roux, que acompanhou as delegações:

\footnotetext{
"Houve uma grande pressão das vítimas da Colômbia pedindo para serem ouvidas e devemos ter em mente que a vitimização na Colômbia foi imensa... O que eu acho interessante é que as partes entenderam que deveriam ouvir as vítimas de todos os lados," (Relatos padre Francisco La Roux apud BRETT, 2017, p. 113).
}

Não era apenas necessário reconhecer as vozes das/os agentes silenciadas/os pelo conflito como uma forma tradicional de empoderamento, mas também de que elas/es soubessem que os receptores de suas mensagens estavam atentos e abertos a escutar o que elas/es tinham a dizer. Evidenciando

7 Os 10 pontos estabelecidos no comunicado foram: reconhecimento das vítimas, reconhecimento de responsabilidade, satisfação dos direitos das vítimas, participação das vítimas, esclarecimento da verdade, reparação das vítimas, garantias de proteção e segurança, garantias de não repetição, princípio de reconciliação e enfoque de direitos. 
assim que, o poder não só se exerce de forma ativa através da fala, mas também da decisão de escuta consciente, tal como afirma Bickford (1996), a escuta e a fala são respostas ativas uma da outra, que se conectam entre si, pelo qual, a escuta assim como a fala é "um ato criativo que envolve um esforço consciente" (BICKFORD, 1996, p. 114).

A receptividade presente na escuta não deve ser vista como sinônimo de passividade, pelo contrário, como anuncia Dobson (2014), trata-se de uma atividade que traz vozes antes desconhecidas à nossa atenção na forma de divulgação, e não de descoberta. Isto é para dizer que as vozes já estavam lá e é simplesmente uma questão de se estar aberta/o à possibilidade de ouvi-las. Nesse sentido, as vozes das vítimas na Colômbia, organizadas politicamente através dos movimentos de vítimas, foram constantemente ignoradas por ambas as partes, mas principalmente pelo Governo Nacional, que deveria resguardá-las e assegurar sua participação em processos de tomada de decisão. No entanto, não quer dizer que essas vozes não existissem, longe disso, elas sempre estiveram presentes, embora a sua materialidade dependesse da possibilidade de serem escutadas com atenção e abertamente, em outras palavras, em consonância com a definição de poder trazida por Pearce (2012), o poder das vítimas também dependia de que as pessoas estivessem ouvindo-as.

Esses dois elementos, a atenção e a abertura, são importantes para entender como a escuta com orientação política pode se converter em uma prática para uma cidadania democrática em uma ordem social diversa e desigual. Bickford (1996) entende que a atenção na escuta política não requer uma renúncia (self-abnegating) das características que nos definem como sujeitos políticos; para a autora, não tem como deixar de lado nossos próprios desejos e vontades, pois a política requer "auto envolvimento com os outros em ação" (BICKFORD, 1996, p. 146). Da mesma forma, a abertura também se relaciona com a forma como interagimos em uma sociedade diversa com múltiplas contradições. Assim, a "abertura envolvida na escuta é (...) uma disposição ativa para construir certas relações de atenção, relações nas quais nenhum de nós temos significado sem o outro" (BICKFORD, 1996, p. 147). Compreender as vítimas do conflito não faz sentido sem entender seus agressores, nem os agressores sem as vítimas. Como conta Jineth Bedoya, jornalista e vítima que viajou na quarta delegação de vítimas à Havana,

Em um processo de paz... é impossível falar de não-repetição se você não tem aqueles afetados, porque aqueles que estão falando lá são quem tiveram o poder das armas... poder ter a visão daqueles que tiveram que suportar o dano maior, além de legitimidade, dá o caminho para o processo (Relato Jineth Bedoya, apud BRETT, 2017, p. 18).

A construção, mas acima de tudo, a reconstrução do tecido social de um país que tem sofrido os estragos de um conflito armado, como no caso da Colômbia, passa necessariamente por processos de comunicação entre os atores envolvidos e por percursos de ressignificação dos acontecimentos do conflito, os quais estariam incompletos sem a participação da sociedade civil. Essa ideia de reconstrução não é simples e demanda uma ampla capacidade dos atores para se dispor a conversar, ou seja, para falar e escutar. Assim, dar poder às vítimas para que elas intervissem no processo de paz, não só significa dispor de alguns espaços de diálogo onde elas pudessem falar, mas sobretudo, significa que as partes que disputavam o poder de fala principal, ambas "vitimizadoras" (o Estado Colombiano e as FARC-EP), se dispusessem honestamente a escutar o que elas tinham a dizer, mesmo que fosse impossível ouvir a todas, pelo menos nesse momento.

Esses processos vinculados à justiça restaurativa, são de acordo com Dobson (2014), onde a escuta mostra mais claramente sua relação direta com o poder, ao reconhecer a presença daquelas "vozes que antes não eram ouvidas, e crucialmente obrigando os outros a ouvir" (DOBSON, 2014, p. 21). No entanto, no diálogo de paz em Havana, não existia uma obrigação jurídica, como acontece muitas vezes em cenários de justiça restaurativa, que obrigasse as partes a ouvir suas vítimas, mas sim, o entendimento de que o processo não poderia avançar sem que houvesse uma vinculação indireta e 
direta, daqueles mais afetados pelo conflito. Nesse sentido, segundo Brett (2017, p. 24), "os fóruns representaram um gesto político e legal em prol da paz, reconhecendo de forma explícita e pública a contribuição que as vítimas poderiam dar ao conteúdo das conversas em Havana (...)". Mostrando assim que, a fala isoladamente não tem poder nenhum se ela não for acompanhada do esforço consciente de escuta de nossos interlocutores, o qual é a forma oposta deles exercer seu poder.

As atividades desenvolvidas no interior dos fóruns foram diversas com o intuito a garantir uma participação ampla e plural. Assim, "essas atividades incluiriam sessões plenárias, oficinas e atos simbólicos de dignificação e reconhecimento dos direitos das vítimas, apresentação de um relatório preliminar sobre as propostas apresentadas e, no caso do Fórum Nacional, painéis com diferentes atores" (ORGANIZAÇÃO DAS NAÇÕES UNIDAS; UNIVERSIDAD NACIONAL DE COLOMBIA, 2014 p. 18). Além disso, organizaram-se mesas de trabalho com participantes diversas/os, privilegiando a participação das vítimas, sobretudo compondo os grupos com vítimas que foram expostas a diversas formas de violência ao longo do conflito. Nesses espaços, houve a abertura para que as/os participantes contassem suas histórias de vida, assim como as motivações que os levaram a se vincular nos fóruns, possibilitando o surgimento de estratégias discursivas como a narrativa de histórias (storytelling), as quais foram amplamente mobilizadas por defensores do processo de paz, que procuraram publicizar histórias do conflito nunca antes contadas, usando-as como estratégia nos fóruns e em meios de comunicação através de propagandas, para sensibilizar o resto da população dos horrores do conflito.

A estratégia das narrativas (storytelling) facilitou a inclusão das vozes de grupos desfavorecidos, como as vítimas das regiões rurais, camponeses e sobretudo mulheres, quem em geral eram marginalizadas/os do debate político mais do que outros atores (POLLETA; LEE, 2006). Assim, a possibilidade de contar e escutar histórias, difíceis de serem contadas e escutadas, mas mesmo assim, desejadas de serem ouvidas, permitiu dar um passo em busca da compreensão e sensibilização das distintas situações que viveram esses agentes no meio do conflito, já que, as "histórias encorajam os ouvintes a entender a perspectiva do contador de histórias" (BLACK, 2008, p. 109). Dessa maneira, a esfera pública e os espaços deliberativos também foram abertos para permitir a participação de seres comuns que contribuem com a reconstrução da memória coletiva da Colômbia, através de suas experiências de vida. Cada uma dessas pessoas foi essencial no processo de paz, pois contribuíram para preencher lacunas históricas, melhorar o entendimento de diversos acontecimentos, mas acima de tudo, ajudaram a curar feridas profundas entre os indivíduos que vivenciaram diretamente o conflito armado.

\section{FEMINISTAS E DEMOCRATAS: CONTRIBUIÇÕES DOS MOVIMENTOS DE MU- LHERES NA RESOLUÇÃO DO CONFLITO NA COLÔMBIA}

Com as alterações nas dinâmicas de construção de paz e a incorporação das vítimas do conflito armado às mesas de negociação (ONU MUJERES, 2017; BRETT, 2017), observou-se uma mudança de postura do governo colombiano em relação à integração das vítimas do conflito no processo de construção da paz. Assim, já no ano de 2014, 60 vítimas foram convidadas para realizar apontamentos e sugestões para a mesa de negociação (ACEVEDO ARANGO, 2017, CALBET, 2018), dando um passo importante para a consolidação da subcomissão de gênero e da adoção de um enfoque diferenciado em cada ponto do acordo de paz proposto.

Nesse momento histórico, as organizações de mulheres e feministas ${ }^{8}$ representaram um importante papel na construção de paz na Colômbia. As organizações realizaram importantes encaminhamentos em

8 Torna-se necessário destacar que a simples presença de mulheres em espaços de negociação não impacta, necessariamente, na produção de melhores condições, seja de representação e/ou reconhecimento, para mulheres em geral. Porém, na Colômbia, através das disputas em diferentes arenas e entre distintas associações de mulheres e de feminismos, que possuem entendimentos plurais no que tange a construção da paz, foi possível criar uma experiência de maior participação, onde as mulheres conseguiram disputar agendas e encaminhamentos durante o processo. 
relação aos direitos das mulheres e o enfoque diferencial de gênero durante os fóruns de vítimas. Por meio da subcomissão de gênero, organizaram-se uma série de reuniões nas quais participaram especialistas e representantes de movimentos sociais, principalmente das organizações de mulheres e lideranças da comunidade de Lésbicas, Gays, Bissexuais, Travestis, Transexuais e Intersexos (LGBTI) do país.

Torna-se relevante, então, apresentarmos de forma breve um panorama geral da participação das mulheres tanto nos fóruns regionais quanto no fórum nacional. Segundo o relatório "Informe y Balance general - Foros Nacional y Regionales sobre victimas" redigido pela Organização das Nações Unidas e pela Universidad Nacional de Colombia (2014), participaram dos encontros cerca de 3.162 pessoas, das quais $48 \%$ eram mulheres e $52 \%$ homens. Nessas esferas de discussão deliberativa, foi firmado entre as/os participantes e a organização, a necessidade de criar uma regra de paridade de gênero entre as/os participantes.

A alta taxa de participação de indivíduos nos fóruns pode ser explicada por alguns motivos, como (i) a necessidade das vítimas em discutir sobre possíveis soluções do conflito, uma vez que existem mais de cinco milhões de vítimas registradas do conflito no país e (ii) porque muitas das vítimas acreditavam que os fóruns seriam o espaço onde se selecionariam as delegações que iriam para Havana (ORGANIZAÇÃO DAS NAÇÕES UNIDAS, UNIVERSIDAD NACIONAL DE COLOMBIA, 2014). Além disso, para as/os participantes, tais espaços seriam locais onde a fala e a escuta eram elementos centrais que contribuiriam pôr fim no conflito, sendo uma chance de falarem sobre experiências e opiniões e de serem ouvidas/os pelas autoridades do Estado Colombiano.

O Fórum Nacional foi resultado direto dos esforços realizados nos fóruns regionais e "do espaço favorável para que as vozes que não puderam comparecer aos fóruns regionais estivessem presentes e que a presença fosse muito mais pluralista" (ORGANIZAÇÃO DAS NAÇÕES UNIDAS, UNIVERSIDAD NACIONAL DE COLOMBIA, 2014, p. 23). Segundo dados do mesmo documento, mais de $70 \%$ dos participantes do Fórum Nacional foram vítimas do conflito armado. Essa cifra foi calculada com base no registro de pertencimento a algum grupo ou setor social vítima do conflito armado, que os participantes dos fóruns fizeram ao início do evento.

Ao que diz respeito a filiação dos participantes do fórum a algum movimento social podemos observar no Quadro 1

Conforme o Quadro 1 pôde-se perceber que os setores com maior representação foram as organizações de mulheres com 99 participantes, seguidas das organizações políticas e sociais e as organizações de afrodescendentes.

Torna-se relevante destacar aqui dois pontos principais. $\mathrm{O}$ primeiro deles diz respeito à necessidade de se levar em conta que os representantes de diferentes setores sociais foram afetados diretamente pelo conflito armado colombiano. Dessa forma, a violência parece ser um ponto estruturador das dinâmicas sociais, uma vez que ela impacta diretamente o cotidiano dos indivíduos, revelando "a natureza transcendental e impactante do conflito na sociedade colombiana como um todo e a importância de reconhecer o impacto do conflito na sociedade em geral" (ORGANIZAÇÃO DAS NAÇÕES UNIDAS, UNIVERSIDAD NACIONAL DE COLOMBIA, 2014, p. 24). O segundo ponto relevante é a alta participação de mulheres e das organizações de mulheres e feministas nesses espaços deliberativos. Como apontado no Quadro 1, as organizações de mulheres foram o principal grupo a participar dos fóruns, porém é necessário ter em mente que as mulheres não limitaram a sua participação dentro das organizações de mulheres, elas estiveram presentes em outras delegações, ocupando posições relevantes seja nos movimentos indígenas, LGBTIs, ambientais, estudantis ou em grupos acadêmicos. Essa participação horizontalizada dos movimentos de mulheres e feministas é um traço marcante do feminismo de quarta onda, como veremos mais à frente.

Assim, segundo Calbet (2018), a participação das mulheres no processo de paz ocorreu a partir de três fronts, sendo eles: (i) por meio das delegações, (ii) através de uma participação de caráter consultivo e (iii) via movimentos de mulheres e feministas. A primeira forma de participação (i) ocorreu de maneira pouco representativa numericamente, inicialmente não havia mulheres ocupando cargos de decisão durante o processo, posteriormente apenas duas mulheres participaram das mesas de negociações. 
Quadro 1. Relação da origem social vs. número de participantes do Fórum Nacional

\begin{tabular}{|c|c|}
\hline \multicolumn{2}{|l|}{ FORO MACIONAL SOBRE VICCTIMAS } \\
\hline SECTOR SOCIAL Y POBLACIONAL & PARTICIPANTES \\
\hline Organizadiones de mujeres & 99 \\
\hline Movimientos politicos y sociales: & 92 \\
\hline Organizaciones afro-descendientes & 70 \\
\hline Organizaciones defensoras de derechos humanos & 62 \\
\hline Organizaciones y movimientos campesinos & 59 \\
\hline Organizaciones indigenas & 58 \\
\hline Gremios y organizaciones del sector empresarial & 48 \\
\hline Partidos y movimiento politicos con personeria juridica & 44 \\
\hline Adolescentes y jovvenes & 43 \\
\hline Iglesias & 36 \\
\hline Organizaciones juveniles & 33 \\
\hline Organizaciones de derechos de niniez & 18 \\
\hline Centrales y organizaciones sindicales & 17 \\
\hline Sector académico, universidades y centros de investigación & 17 \\
\hline Programas de Desarnollo y Paz e Iniciativas Nacionales y territoriales de paz & 16 \\
\hline Directivos de medios de comunicación y sus asociaciones & 11 \\
\hline Organizaciones de raizales, palanqueros y Rom & 7 \\
\hline Organizaciones L.GBTI & 7 \\
\hline Organizaciones ambientalistas & 2 \\
\hline Total & 739 \\
\hline Porcentaje del total de participantes & $51 \%$ \\
\hline
\end{tabular}

Fonte: Organização das Nações Unidas; Universidad Nacional de Colombia, 2014, p. 23-24

A segunda forma de participação (ii) deu-se por meio de cargos consultivos. Por meio desse front, as mulheres foram capazes de participar dos fóruns temáticos, das delegações de vítimas e das discussões em Havana ocupando posições de especialistas. A participação nesse eixo de atuação possibilitou às mulheres influenciar diretamente na escrita do documento final. Por fim, a terceira via de participação (iii) deu-se pelos movimentos de mulheres e feministas, que conseguiram organizar duas "Cumbres de Mujeres y Paz", construindo redes e espaços onde se tornou possível debater e contribuir para formulação de propostas que foram apresentadas para a mesa de negociação, além da coordenação de campanhas de conscientização sobre o processo de paz e seu impacto para a população (CALBET, 2018).

Essas redes construídas pelas organizações possibilitaram a incorporação de vários aspectos relacionados com os direitos das mulheres nos acordos de paz. Assim, o processo na Colômbia pode ser apontado como aquele que mais contou com a participação popular nos últimos anos. E o documento final pode ser entendido como um dos mais avançados no que tange a temática de gênero, demonstrando a prioridade das partes envolvidas no conflito em reconhecer o papel das vítimas na resolução do conflito armado (FISAS, 2016; CALBET, 2018). A inclusão e a participação das mulheres nesses fóruns deliberativos e de escuta foram essenciais para que suas vozes e experiências fossem reconhecidas, o que impactou fortemente a formulação das políticas inseridas no acordo de paz.

Ao postular a necessidade de se construir a paz por meio da participação popular, levando em consideração as experiências individuais e coletivas dos indivíduos que vivenciaram diferentemente 
o conflito colombiano, as organizações feministas assumem um importante papel na construção de uma democracia mais participativa e inclusiva no país. Os movimentos de mulheres e feministas na Colômbia buscaram construir relações com outros movimentos sociais, como o movimento negro, LGBTI, indígena, e de forma convergente foi capaz de mobilizar e organizar demandas diversas e plurais em uma luta conjunta.

Essa tentativa de organizar ações conjuntas entre os movimentos é trabalhada por Butler (2018) ao sugerir que determinados grupos minoritários (e subordinados) deveriam se engajar em lutas conjuntas por justiça social. As alianças seriam formadas pelas diversidades das populações minoritárias, expostas a condições de precariedade. O estabelecimento de ligações entre a "diversidade de sua própria população e todas as ligações que isso implica com outras populações sujeitas a condições [...] precária[s]" (p.77) devem ser adotadas enquanto estratégia dos movimentos sociais, se já não o são. Apontando a caráter interseccional das lutas na contemporaneidade, mecanismo adotado principalmente pelos movimentos de gênero e sexualidade. Assim, para Matos (2014), os movimentos de mulheres e feministas na América Latina surge e se desenvolve a partir das fronteiras da interseccionalidade, transversalidade e transdisciplinaridade entre as categorias de gênero, raça, sexualidade, classe e geração.

Os discursos e práticas mobilizadas pelos movimentos "reconhecem a interseccionalidade das diferenças como dado inescapável e como força politizadora das lutas sociais" (MATOS, 2014, p. 4), não sendo mais possível pensar em lutas desconexas e autônomas entre si. Esse novo desenho das alianças seria marca do que algumas autoras (ALVAREZ, 2014; MATOS, 2010, 2014; MATOS, PARADIS, 2014) compreendem como quarta onda do feminismo latino-americano.

Atualmente, o feminismo teria não apenas passado por um processo transversalizado, ao ser inserido de forma transdisciplinar nas agendas de atores estratégicos, mas teria também se verticalizado (mainstreaming), o que poderia ser observado a partir de fluxos verticais por meio dos quais os discursos e práticas passam a circular de forma ampla em diversas instâncias como nos partidos políticos, nas arenas estatais e no sistema internacional, mas também se horizontalizado (sidestreaming), permitindo que práticas e discursos dos feminismos chegassem a diversos setores da sociedade civil (ALVAREZ, 2014; MATOS, 2010). Esse alargamento teórico-conceitual-prático-discursivo possibilitaria a ocupação de atoras e ideais feministas nas mais diversas arenas da sociedade.

Essa participação das mulheres em diferentes instâncias possibilita a essas agentes trazer um novo olhar interseccional a partir de experiências individuais que são marcadas tanto pelas práticas de gênero, raça, classe, geração e sexualidade como pela vivência das mulheres em contextos de violações de direitos humanos durante o conflito armado - o que contribuiu para se pensar no enraizamento da democracia no país. Nesse sentido, no caso colombiano por exemplo, esses marcadores sociais da diferença acabaram por se fazer presente nas esferas deliberativas, sejam nos fóruns ou nas conferências, por meio das falas das/os participantes, o que posteriormente foi integrado no documento final do acordo de paz.

Assim, fundamentada na discussão da inclusão das experiências das mulheres na arena política, Flávia Biroli (2016) compreende que quando os limites da democracia são analisados a partir da perspectiva das mulheres, ou seja, a partir de suas vivências diferenciadas, é possível expor as conexões entre as relações de poder em diversas esferas da vida e os obstáculos à participação política e à cidadania. Para a autora, uma democracia feminista é aquela capaz de criar mecanismos que superem os obstáculos impostos às mulheres, tendo em mente que não são barreiras exclusivas de gênero, mas que perpassam importantes marcadores como classe, sexualidade, raça, dentre outros. Assim, o fortalecimento de uma democracia ocorreria a partir da valorização das experiências e das vozes das mulheres que são negras, brancas, indígenas, migrantes, ricas, pobres e diversas.

Toda a discussão realizada acima encontra-se profundamente vinculada ao nosso caso de análise. Foi por meio do reconhecimento da necessidade de incluir vozes plurais, com vivências diversas do 
conflito armado, que o acordo de paz se estruturou de modo a inserir um enfoque de gênero em cada um dos seis pontos do acordo, o que só se tornou possível quando as mulheres passaram a disputar um lugar de fala e voto nos espaços de decisão. A proposição da primeira versão do acordo de La Habana é um claro exemplo da forma como os movimentos feministas na Colômbia se articulou com diversos outros movimentos sociais criando alianças no intuito de contribuir para a construção de uma realidade mais justa para os indivíduos de grupos minoritários.

\section{APONTAMENTOS FINAIS}

A existência de uma série de fóruns, conferências, cúpulas e assembleias, diferenciadas, mas interconectadas, influenciaram positivamente na construção da paz na Colômbia, ao possibilitar que uma polifonia de vozes fosse ouvida e que suas experiências passassem a incorporar o acordo. Nesse contexto, se destaca a ação e participação das mulheres de forma individual e coletivamente por meio dos movimentos, as quais nutriram o processo com informações antes ignoradas e silenciadas sistematicamente, sem as quais, a resolução do conflito em Colômbia seria uma tarefa incompleta.

Assim, o Documento Final do Acordo de Paz entre o Governo de Colômbia e a FARC-EP, está impregnado pelo reconhecimento do papel da mulher na construção da sociedade colombiana, como cidadãs autônomas e agentes de direitos, o qual se denota desde a forma como o documento foi redigido, sempre fazendo uso da escrita inclusiva - "homens e mulheres, meninos e meninas, etc." - até na declaração explicita deste reconhecimento. Como por exemplo, no ponto 1 do Acordo que compete a Reforma Rural Integral (RRI):

A RRI reconhece o papel produtivo e reprodutivo das mulheres e, nesse sentido, seu papel fundamental no desenvolvimento e na economia rural, e fará maiores esforços para que elas e as populações mais vulneráveis garantam condições de bem-estar e boa vida e fortaleçam suas formas de organização e produção. (DELEGADOS GOBIERNO DA COLÔMBIAFARC-EP, 2016, p.11)

O enfoque diferencial e de gênero se fez presente no Acordo de Paz ao longo dos seus 6 pontos principais graças à influência e participação organizadas das mulheres através dos movimentos sociais, que buscaram ampliar as bases do processo de paz para que fosse mais inclusivo e superasse as barreiras estruturais que separam grupos tidos como marginalizados da participação ativa no processo político nacional. Desta maneira, já no início do documento as delegações do Governo Nacional da Colômbia e das FARC-EP reiteram seu agradecimento profundo a essa pluralidade de atores que participaram ativamente na construção do acordo, como foram "todas as vítimas, organizações sociais e de direitos humanos, comunidades incluindo grupos étnicos, organizações de mulheres, camponeses e camponesas, jovens, acadêmicos, empresários, igrejas e comunidades de fé, (...)" (DELEGADOS GOBIERNO DA COLÔMBIA- FARC-EP, 2016, p.9).

A criação de alianças e de superação de desigualdades foi importante no fazer político das mulheres na Colômbia. Sua participação não só nos movimentos feministas, mas também em outros movimentos sociais, explicada pela interseccionalidade, transversalidade e transdisciplinaridade das pautas que as interpelam, permitiu sua participação diferenciada e pluralizada ao longo do processo de paz, tendo impactos na estrutura social colombiana de forma geral. Uma das estratégias importantes desses grupos, esteve na valorização das experiências, construindo espaços onde a escuta e a fala foram base para a construção de uma outra política. Assim, os movimentos de mulheres e feministas tem se caracterizado por reinventar as práticas e discursos, trazendo uma nova possibilidade de ação política coordenada.

Por fim vale ressaltar que ao lançarmos mão de múltiplas teorias de democracia, não compreendemos as teorias como macro-explicações completas e independentes, mas sim, compreendê-las enquanto 
formulações que estabelecem ligações e se complementam umas com as outras. Assim, ao analisar o caso da participação das mulheres na construção de paz na Colômbia, percebemos por exemplo, que não seria possível pensar uma democracia funcional, desde o ponto de vista feminista, onde a escuta e a possibilidade de debates plurais não sejam pontos centrais. Ou então, que não seria possível pensar em uma democracia deliberativa que não levasse em conta a importância das experiências dos indivíduos, principalmente das mulheres, entendendo-as como agentes diversos e historicamente silenciados, e que não estivesse aberta para o exercício de escuta de demandas e opiniões muitas vezes antagônicas.

Denotamos finalmente que, para entendermos os atuais contextos democráticos torna-se necessário ter em mente as possibilidades de formulação de "pontes compreensivas" entre as construções teóricas já existentes. Dessa maneira, poderemos construir instrumentais analíticos mais complexos que nos permitam entender as novas formas de organizações da vida política e social contemporânea. No caso colombiano, os movimentos de mulheres e feministas colocaram em discussão, de forma não intencional aos propósitos da academia, a importância de conjugar diferentes estratégicas para possibilitar uma ação política mais inclusiva. Suas implicações no cotidiano ainda precisam ser objetos de outros estudos, no entanto o caso trouxe importantes aportes, tornando-o interessante e frutífero para continuar sendo estudado. 


\section{Referências}

ACEVEDO ARANGO, O. F. El corazón de las víctimas. aportes a la verdad y la reconciliación para Colombia. Comisión de Conciliación Nacional. Bogotá, 2017.

ALVAREZ, Sonia E. Para além da sociedade civil: reflexões sobre o campo feminista. Cad. Pagu, Campinas, n. 43, p. $13-56,2014$

BICKFORD, S. The Dissonance of Democracy: Listening, Conflict, and Citizenship. New York: Cornell University, 1996.

BIROLI, Flávia. Redefinições do público e do privado no debate feminista: identidades, desigualdades e democracia. In: MIGUEL, Luis Felipe (org.). Desigualdades e Democracia: o debate da teoria política. São Paulo: Editora Unesp, 2016.

BLACK, Laura W. Deliberation, Storytelling, and Dialogic Moments. Communication Theory 18, 2008.

BRETT, Roddy. La voz de las victimas en la negociación: sistematizacion de una experiencia. Programa de las Naciones Unidas para el Desarrollo, 2017.

BOSWELL, John. Why and how narrative matters in deliberative system? Political Studies, vol. 61, 3: pp. $620-636$. 2012.

BUTLER, Judith. Corpos em aliança e a política das ruas. RJ: Civilização Brasileira, 2018.

CALBET, Néstor. La violencia sexual en Colombia, mujeres víctimas e constructoras de paz. Institut de Drets Humans de Catalunya, Barcelona, 2018.

COMUNICADO CONJUNTO NO. 37. "Declaração de princípios para a Discussão do ponto 5 da Agenda: Vítimas", 2014 .

COHEN, J. Procedure and substance in deliberative democracy. In: BOHMAN, J. (ed). Deliberative democracy: Essays on reason and politics, 1997, vol. 407.

DELEGADOS GOBIERNO DA COLÔMBIA - FARC-EP. Acordo geral para a terminação do conflito e a construção de uma paz estável e douradoura, 2012.

DELEGADOS GOBIERNO DA COLÔMBIA - FARC-EP. Acuerdo final para la terminación del conflicto y la construcción de una paz estable y duradera. Gobierno Nacional de Colombia, 2016.

DOBSON, A. Listening for Democracy- Recognition, Representation, Reconciliation. New York: Oxford University Press, 2014.

DRYZEK, J. S. Democratization as deliberative capacity building. Comparative political studies, 2009, vol. 42, no 11, p. $1379-1402$.

Rhetoric in Democracy: A Systemic Appreciation. Political Theory 38(3) 319-339, 2010

FISAS, Vicenç. Negociar la Paz con las FARC. Icaria. Barcelona, 2016

FISCHER, F. Passionate Participants: Rethinking Emotions in Public Deliberation. IN: Fischer, F. Democracy and Expertise. Reorienting Policy Inquiry. 2009.

GALTUNG, Johan. Peace by peaceful means: Peace and conflict, development and civilization. SAGE, 1996.

HEIDELBERG INSTITUTE FOR INTERNATIONAL CONFLICT RESEARCH (HIIK). Conflict Barometer 1992.

Heidelberg, Alemanha. 
Conflict Barometer 2018. Heidelberg, Alemanha.

HUMANAS COLOMBIA. Cinco claves para un tratamiento diferenciado de la violencia sexual: corto animado. 2016. 3:38. Disponível em: <https://www.youtube.com/watch?reload=9\&v=ECT2QrQ31FI >. Acesso em: 20 jul. 2018.

\section{HUMANAS COLOMBIA, CORPORACIÓN SISMA MUJER, RED NACIONAL DE}

MUJERES. Cinco claves para un tratamiento diferencial de la violencia sexual en los acuerdos sobre la justicia transicional en el proceso de paz. 2016. Disponível em: $<$ http://www.humanas.org.co/archivos/Cinco_claves_de_la violencia_sexual_en_los_acuerdos_sobre_justicia_transicional-resumenejecutivol.pdf >. Acesso em: 10 jul. 2018.

KRAUSE, Sharon R. Civil Passions: Moral Sentiment and Democratic Deliberation. Princeton, NJ: Princeton University Press, 2008.

MATOS, Marlise. Movimento e Teoria Feminista: É possivel reconstruir a teoria feminista a partir do Sul Global? Revista de Sociologia e Política, v. 18, n 36: 67-92, jun. 2010.

MATOS, Marlise. A Quarta onda feminista e o Campo crítico-emancipatório das diferenças no Brasil: entre a destradicionalização social e o neoconservadorismo político.In: Anais $38^{\circ}$ Encontro Anual da ANPOCS. 2014.

MATOS, Marlise; PARADIS, Clarissa Goulart. Desafios à despatriarcalização do Estado brasileiro. Cadernos Pagu (43), 57-118, 2014.

MENDONÇA, Ricardo Fabrino; SANTOS, D. B. A cooperação na deliberação pública: um estudo de caso sobre o referendo acerca da proibição da comercialização de armas de fogo no Brasil. Dados (Rio de Janeiro), v. 52, n.2, p. 507-542, 2009 .

MENDONÇA, R. F. Antes de Habermas, para além de Habermas: uma abordagem pragmatista da democracia deliberativa. Sociedade e Estado, 2016, vol. 31, no 3, p. 741-768

ORGANIZAÇÃO DAS NAÇÕES UNIDAS; UNIVERSIDAD NACIONAL DE COLOMBIA. Informe y Balance General - Foros Nacional y Regionales sobre víctimas. Impresol Ediciones: Colômbia, 2014.

ONU MUJERES. 100 medidas que incorporan la perspectiva de género en el acuerdo de paz en colombia. Organização das Nações Unidas: Colômbia, 2017.

PEARCE, Jenny. Power and the Activist. Development, v. 55, n. 2, p. 198-200, 2012.

PEREZ, V. B. Procesos de Paz en Colombia. Fundación Paz y Reconciliación. 2018. Disponível em: < https://pares.com.co/2019/01/04/procesos-de-paz-en-colombia/https://pares.com.co/2018/04/17/procesos-de-paz-en-colombia/>. Acesso em: 14 de dezembro de 2018.

POLLETTA, F.; LEE, J. Is telling stories good for democracy? Rhetoric in public deliberation after 9/11. American Sociological Review, 2006, vol. 71, no 5, p. 699-721.

RYFE, David M.. Narrative and Deliberation in Small Group Forums. Journal of Applied Communication Research $34,2006$.

STEINER, J. et al. Deliberation across deeply divided societies. Cambridge University Press, 2017.

URIBE CELIS, C. ¿Regeneración o catástrofe? (1886-1930). In: RODRÍGUEZ, L. E. et al. História de Colombia: todo lo que hay que saber, Grupo Santillana SA, Bogotá, 2011.

VIANNA, Adriana. Etnografando documentos: uma antropóloga em meio a processos judiciais. In: CASTILHO, Sérgio R. R.; LIMA, Antonio C. S.; TEIXEIRA, Carla C. (orgs.). Antropologia das Práticas de poder: reflexões etnográficas entre burocratas, elites e corporações. Rio de Janeiro: Contra capa, 2014.

VINYAMATA, Eduard. Conflictología: curso de resolución de conflictos. Grupo Planeta (GBS), 2014. 
YOUNG, Iris Marion. Justice and the Politics of Difference. Princeton, NJ: Princeton University Press, 1990.

Communication and the other: Beyond deliberative democracy. Democracy and difference: Contesting the boundaries of the political, 1996, vol. 31, p. 120-135.

WORLD INEQUALITY DATABASE. Top 1\% national income share. Disponível em: < https://wid.world/world\#sptinc_p99p100_z/US;FR;DE;CN;ZA;GB;WO;CO/last/eu/k/p/yearly/s/false/4.8255/30/curve/false/country >. Acesso em: 12 de dezembro de 2018.

\begin{tabular}{|ll}
\hline Histórico & Recebido em: 25/08/2019 \\
& Revisado em: 07/10/2019 \\
& Aceito em: 28/10/2019 \\
& Concepção: PB; YMV \\
& Coleta de dados: PB; YMV \\
& Análise de dados: PB; YMV \\
Contribuição & Elaboração do manuscrito: PB; YMV \\
& Revisões de conteńdo intelectual importante: PB; YMV \\
& Aprovação final do manuscrito: PB; YMV \\
& \\
& Pedro Barbabela (Bolsista Capes - Código de Financiamento 001) e Yulieth Martínez \\
& Villalba (Bolsista do Programa PEC-PG CNPq - Bolsa número 190275/2017-0) \\
\hline
\end{tabular}

